\title{
Analysis of the Factors Affecting the Initial Price of PPP Expressway
}

\author{
Zhongfu Qin ${ }^{1, a}$ and Xiaodong $\mathrm{Wu}^{2, \mathrm{~b}}$ * \\ ${ }^{1}$ Zhejiang University ,866 Yuhangtang Road, Hangzhou, Zhejiang Province, China \\ ${ }^{2}$ Room AnzhongA525,Zijinggang Campus of Zhejiang University, Hangzhou, Zhejiang Province, \\ China \\ aqinzhongfu@zju.edu.cn, b21612215@zju.edu.cn,
}

Keywords: PPP mode; The Initial Price ;Influential factors

\begin{abstract}
In order to make clear influencing factors of the expressway initial price based on PPP model, according to different concession price impact mechanism, three first level factors are figured out by the use of literature review and systematic analysis, including overall environment, core participants of the project, and infrastructure features. After that, we analyze each factor separately.
\end{abstract}

\section{Introduction}

Adopting the PPP mode to construct expressway, the private sector is mainly responsible for the construction the project, the operation and maintenance management during the franchise period. There are mainly two ways to recover investment and get a reward: based on government-paid and user-paid. In view of the current situation in our country, the PPP mode mostly adopts the second way, so this paper mainly discusses the user-paid PPP mode. In this mode, concession price is a key element as a criterion for charging road users, not only as an important evaluation criterion in the selection of partners, but also affects the interests of all parties involved in the project, the construction and operation of the project, which is the key to determine the success or failure of the project. Reasonable charging standards should not only prevent the private sector from losing money or earning hugh profits, but also maximize the social benefits.

During the progress of the project, the concession price needs to be adjusted according to the deviation between the actual situation and the expectation. One of the first is to determine an initial price as the charging standard in the initial stage of the operation. The determination of the initial price should follow the market discipline, but at the same time, it is influenced by many factors. The influence factors of the initial price are the various factors that affect the determination of the initial price when the initial price is formed. In the literature about the concession price of the PPP mode, the past researchers haven't systematically discussed the influence factors of the initial price, nor have they reached a unified understanding. And determining the initial price is an unavoidable issue in the PPP project. Based on this, this paper sets the influence factors of the initial price as research object, and systematically discusses the various factors and ways that influencing the initial price, and provides the reference for the determination of the initial price.

\section{Literature Reviews}

For the initial price, according to structural equation modeling and analysis, Duan Shixia, etc. suggests that the determination of concession price for PPP project should consider economic, political / legal, technical conditions, government, private sector, public and project itself characteristics[1]. But Wanghao proposes to determine the starting price according to the control model of Return On Investment on the basis of operating cost, and fully consider the income affordability of residents, the existing price level of competitive routes and the price level of other regions[2]; Chen Patriotic, etc. proposes that the basic principle of price determination is to ensure that adequate products and services are provided to consumers at a price as reasonable as possible, while encouraging project companies to devote themselves to development and operation[3]. Li Baoqiong believes that the formation of price 
should be based on the total cost, take the rational allocation of resources as the principle, take the local economic level and public affordability into account, and at the same time, the interests of the project company should not be ignored[4].

The analysis of the initial price in the above study has the conditions to be considered in determining the price, the basic principle of price determination, and the composition of the price. This paper is an analysis of the factors affecting the initial price. The consideration conditions of price determination can be regarded as the factors that affect the formation of price. The basic principle and price composition are not equal to the influence factors. But each part of the price composition is extracted separately, it can be seen as an influential factor. For example, the formation of the price is based on the total cost, and the starting price is determined according to the investment return control model, then the total cost and the return on investment are the influencing factors of the price formation. According to this rule, collating the above literature preliminarily get the aspects to be considered to determine initial price.

\section{Sum up the Ideas}

The principle of factor collation is to make the classification of influencing factors of initial price meet the requirements of completeness, independence and systematization.

There are five methods of summing up factors: retention, deletion, addition, modification and consolidation. The criteria for summing up process is that: according to the correlation of the influence on the initial price, the factors that have direct influence are classified as the first class factor, the indirect influence (influenced through the first class factor) is the second class factor, and so on. In view of the above factors, first of all, the factors which are relevant to the initial price are retained, and the irrelevant factors are deleted. For the next level of a factor, if there is no comprehensive summary of the correlation between the two levels of the relationship, the factor will be added; And modify the factors that are not standardized in expression and are not unified with other factors in the same level; Merge elements that duplicate content or are different expressions of the same concept.

Analysis the viewpoints above, the economic condition, political condition, legal condition and local economic level are the background of the project. The PPP project should be adapted to the economic, political and legal environment of one location. Those are environmental factors; The technical condition, project's own characteristic, the operation cost, total cost and the project construction object are closely related to the project construction object. The specific infrastructure / service provided by the PPP project determines the technical condition, its own characteristic and the cost of the project. It is the characteristic of infrastructure / services; The government, private sector and the public are the main participants of the project and interested party of the PPP project. The rate of return on investment belongs to the relevant interests of the project participants and it's one of the objectives for one of the parties to participate in the PPP project. Residents' income affordability is an important factor for the project participants to use the basic services / facilities of the PPP project through payment. The price level of the competitive route affects the revenue of the infrastructure in the operation process, but the monopoly and intense competition varies greatly among different projects. Providing the abundant product and services at a reasonable price, the reasonable allocation of resources takes the interests of consumers into account, which is related to the users and belongs to the main factors of project participation; Motivating the project company development and operation are similar with the project company benefit and the investment rate of return. Only the project participation main body could obtain profits, the PPP project could carry on smoothly. Based on the above analysis, the factors influencing the formation of the initial price are divided into three categories: the overall environment, the core participants of the project and the characteristics of infrastructure / services. These three types of factors have a direct impact on the formation of the initial price, so they are the first level of factors.

In the overall environment, the local economic level and economic conditions are all describing the regional economy, which belongs to the different expressions for same concept, so combine them, and unified express as economic conditions; The public affordability is closely related to the local economic level. The higher the local economic level, the higher the public affordability, so the public affordability is the element of the next level of economic conditions, that is, the third level factor. 
Among the core participants of the project, the government, the private sector and the public are three independent participants, they are as the second level factor; Providing abundant products and services at a reasonable price, and the reasonable allocation of resources is the social benefit of PPP project, and the social benefit is the main goal that the government should achieve in carrying out the PPP project. So those two factors are the next level factors of government; Profit is the biggest motivation to attract the private sector to participate in the PPP project, so the return on investment and the income of the project company are mainly considered from the perspective of the private sector and are the factors of the next level of the private sector. Residents' income affordability is an aspect that reflects the degree of public participation in PPP projects. The higher the residents' income affordability, the wider the acceptable range of price changes to the public, which is the next level of factors for the public.

In the characteristic of infrastructure / service, the total cost is composed of the total input of the construction stage and the operating cost, so the total cost is regarded as the second level factor, and the operating cost as the third level factor below the total cost. At the same time, the construction cost is added as the third level factor in parallel with the operating cost; The characteristics of the project itself are similar to the infrastructure / service, and are expressed uniformly by the characteristics of the infrastructure / service; The concept of competitive route applies to the particular case of general provincial roads, which is modified to be a competitive project, that is, a similar project in which there is a competitive relationship with the project.

According to the above analysis, we can get Figure 1.

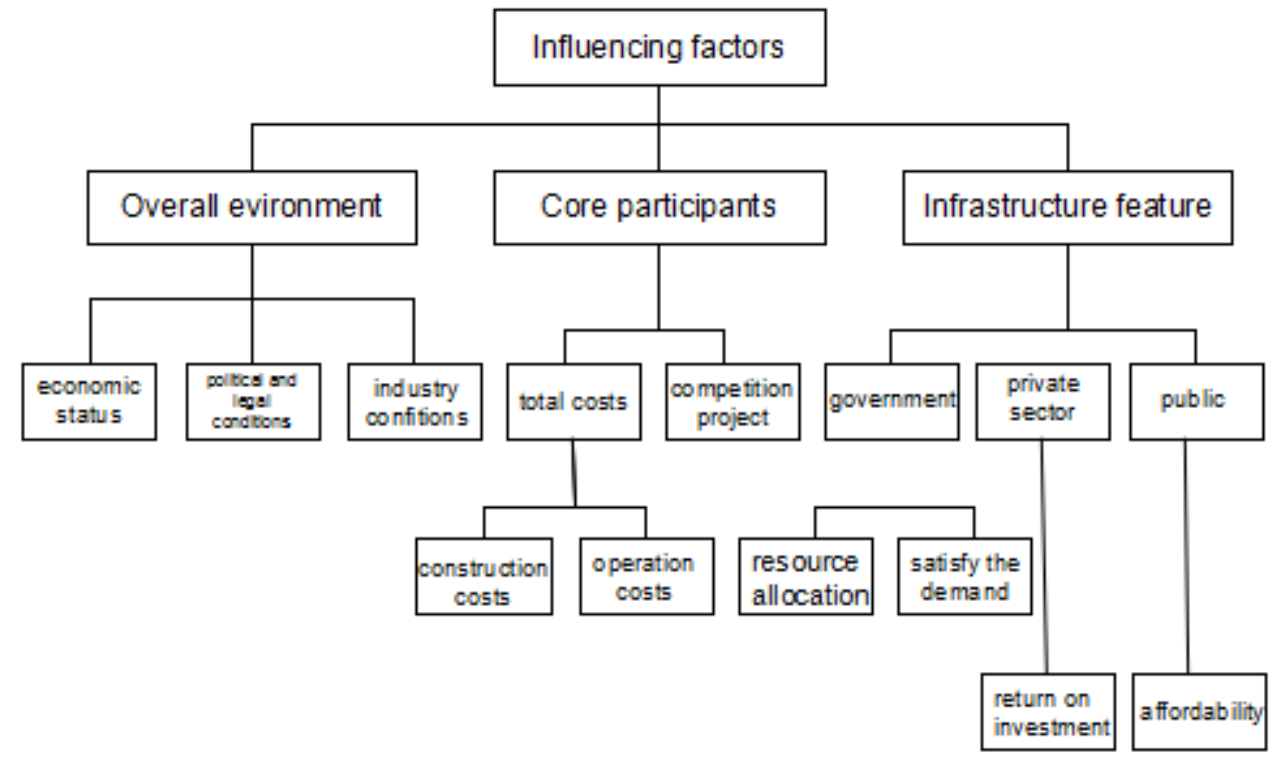

Figure 1. Classification of influencing factors

\section{Summary}

In order to make clear influencing factors of the expressway initial price based on PPP model, according to different concession price impact mechanism, three first level factors are figured out by the use of literature review and systematic analysis, including overall environment, core participants of the project, and infrastructure features. After that, This article made a more detailed breakdown of each of these factors. 


\section{References}

[1] S.X.Duan, X.Fang: Journal of Industrial Technological Economics, Vol. 41 (2014) No.7, p.88.

[2] H.Wang: Urban Rapin Rail Transit, Vol. 3 (2004) No.3, p.81.

[3] A.G.Chen,Y.J.Lu: Construction Economy, Vol. 5 (2006) No.3, p.77.

[4] B.Q.Li: Entrepreneurs World, Vol. 9 (2014) No.3, p.105.

[5] W.X.Xu: Freeway and Regional Social Economic Development (China Railway Publishing House,China,2009), p.252.

[6] C.W.Sun: Research on expressway toll pricing-Guangdong as a example (MS., Jinan University, China 2007), p.27.

[7] P.C.Yao, S.J.Wang: Price: Theory \& Practice, Vol. 3 (2011) No.4, p.81.

[8] B.Song, F.Xu: Journal of Management Sciences in China, Vol. 14 (2011) No.1, p.86.

[9] X.Yi: Technology Economics, Vol. 34 (2015) No.12, p.108.

[10] S.Y.Duan, F.Xie: Journal of Industrial Technological Economics, Vol. 20 (2014) No.7, p.117. 